\title{
СУЩНОСТЬ И ИНСТРУМЕНТЫ АНТИКРИЗИСНОГО МЕНЕДЖМЕНТА
}

\author{
(c) 2018 Захарченко Игорь Сергеевич \\ аспирант \\ Ленинградский государственный университет имени А.С. Пушкина \\ 196605, г. Санкт-Петербург, Пушкин, Петербургское шоссе, 10 \\ E-mail: 193miller@gmail.com
}

В статье рассмотрены существующие подходы по определению сути антикризисного менеджмента предприятия; предложена его трактовка как совокупности управленческий решения и действий, нацеленных на прогнозирование и выявление сигналов возможных угроз, диагностику кризисного состояния предприятия, разработка и внедрение способов предупреждения и подавления негативных последствий. Охарактеризованы инструменты антикризисного менеджмента операционного, тактического и стратегического уровней.

Ключевые слова: предприятие, антикризисный менеджмент, процесс антикризисного менеджмента, инструменты антикризисного менеджента.

Сегодня деятельность любого предприятия зависит от большого количество факторов, которые могут создать кризисную ситуацию и ухудшить показатели его деятельности. Опыт развития экономических систем разного уровня показывает, что кризисное состояние - это один из этапов их функционирования, поэтому понимание процессов, которые происходят как во внутренней, так и во внешней среде экономической системы позволяет заблаговременно выявить угрозу наступления кризиса, предупредить его или разработать и реализовать меры по минимизации возможных негативных последствий. Необходимость мониторинга рисков, предвидения угроз и своевременная реакция обусловили формирование отдельного направления в менеджменте - антикризисного. Именно поэтому вопрос антикризисного менеджмента для отечественных предприятий является актуальным.

Целью исследования является обобщение существующих подходов к определению сущности и инструментов антикризисного менеджмента предприятия. Основными задачами исследования являются: изучение и обобщение существующих подходов к определению сущности антикризисного менеджмента (управления); определение элементов системы антикризисного менеджмента (объекта, субъекта, предмета, цели, принципов, функций, критериев, инструментов), основных этапов его осуществления; характеристика инструментов антикризисного менеджмента операционного, тактического, стратегического уровня.
В исследованиях антикризисное управление и менеджмент рассматриваются с разных позиций и подходов. Так сторонники системного подхода считают, что антикризисное управление деятельностью предприятия должно основываться на теории возникновения и углубления кризиса. Субъект антикризисного менеджмента должен четко понимать свое место и функции в общем механизме функционирования предприятия как системы, обеспечивая своевременное выявление и устранение признаков кризисного состояния.

Так, А. Грязнова, М. Федотова, А. Маринюк определяют антикризисное управление как систему управления предприятием, которая имеет комплексный характер и направлена на избежание или устранение неблагоприятных для бизнеса явлений с помощью использования всего потенциала современного менеджмента, разработки и реализации на предприятии специальной программы, которая имеет стратегический характер и позволяет устранить временные трудности, сохранить и улучшить рыночные позиции предприятия при любых обстоятельствах с использованием преимущественно собственных ресурсов. Антикризисное управление предприятием предусматривает ускоренное и действенное реагирование на существенные изменения внешней и внутренней среды на основе заблаговременно разработанных антикризисных мер [4, с.7].

Ситуационный подход к антикризисному менеджменту сосредотачивает внимание на использовании специальных приемов и методов, 
целесообразных в конкретных обстоятельствах, которые влияют на предприятие в данный период времени. Так, Л. Лигоненко рассматривает антикризисное управление как специальное, постоянно организованное управление, нацеленное на оперативное выявление признаков кризисного состояния и создание соответствующих условий для его своевременного преодоления с целью обеспечения восстановления жизнедеятельности отдельного предприятия, недопустимости возникновения ситуации его банкротства [5, с.37].

Процессный подход антикризисного менеджмента позволяет определить его этапы как процесс и разработать для каждого соответствующие инструменты. А. Градов трактует его как совокупность последовательных обобщенных антикризисных мер, таких как: анализ состояния макро- и микросреды, выбор миссии предприятия; изучение механизма возникновения кризисных ситуаций и создание системы мониторинга внешней и внутренней среды предприятия для раннего выявления слабых сигналов кризиса; стратегический контроллинг деятельности предприятия и разработка стратегии избежания его неплатежеспособности; оперативная оценка и анализ финансового состояния предприятия, выявление вероятности возникновения банкротства; разработка системы действий в условиях кризиса для выхода из кризисной ситуации; постоянный учет риска предпринимательской деятельности и разработка мер для его снижения [2, с.84].

О. Непочатенко трактует антикризисный менеджмент с позиции институционного подхода - как процесса использования форм, методов и процедур, направленных на социально-экономическое оздоровление финансово-хозяйственной деятельности индивидуального предпринимателя, предприятия, отрасли, создание и развитие условия для выхода из кризисного состояния экономики региона или страны в целом [7].

Функциональный подход базируется на уточнении содержательного наполнения традиционных функций менеджмента (планирование, организация, мотивация, контроль) в условиях обострения ситуации и возможности ухудшения результатов деятельности предприятия.

Обобщая можно сказать, что антикризисный менеджмент - это совокупность управленческих решений и действий, нацеленных на прогнозирование и выявление сигналов возможных угроз, диагностику кризисного состояния предприятия, разработку и внедрение мер для предупреждения и снижения негативных последствий. Составляющие антикризисного менеджмента представлены в табл. 1.

Учитывая разнообразие кризисных явлений и наличие разных вариантов их проявления

\section{Таблица 1. Составляющие системы антикризисного менеджмента}

\begin{tabular}{|l|l|}
\hline Объект & $\begin{array}{l}\text { Предвидение и реальные причины кризиса, факторы которые его вызывают, послед- } \\
\text { ствия к которым он приводит }\end{array}$ \\
\hline Субъект & $\begin{array}{l}\text { Лица, которые владеют знаниями, компетенцией и необходимыми ресурсами, осу- } \\
\text { щестляют целенаправленные действия с целью обеспечения устойчивости предприя- } \\
\text { тия к негативным изменениям }\end{array}$ \\
\hline Предмет & $\begin{array}{l}\text { Совокупность взаимоотншений между субъектами антикризисного управления, соз- } \\
\text { данных на предприятия, по отношению к формам, методам и средствам влияния на } \\
\text { объект антикризисного управления }\end{array}$ \\
\hline Цель & $\begin{array}{l}\text { Обеспечение высокого уровня устойчивости, гибкости, адаптивности предприятия для } \\
\text { недопустимости негативных изменений }\end{array}$ \\
\hline Принципы & $\begin{array}{l}\text { Последовательности действий, постоянного присмотра, адаптируемости, динамично- } \\
\text { сти, согласованности действий, оптимальности, временных ограничений, конструктив- } \\
\text { ности, адресности, завершенности }\end{array}$ \\
\hline Функции & $\begin{array}{l}\text { Выявление признаков кризиса, определение степени негативного влияния; разработка } \\
\text { антикризисной программы; организация деятельности; контроль за ее реализацией; } \\
\text { мотивация персонала к активным действиям для преодоления кризиса; корректирую- } \\
\text { щие действия; оценка эффективности антикризисных мер и управленческих решений }\end{array}$ \\
\hline Критерии & $\begin{array}{l}\text { Достижение изменений важнейших показателей, скорость получения положительных } \\
\text { изменений на единицу времени, экономичность получения положительного эффекта, } \\
\text { достаточность изменений для восстановления параметров жизнеспособности пред- } \\
\text { приятия, скорость адаптации социально-экономической системы к изменениям [6] }\end{array}$ \\
\hline Инструменты & $\begin{array}{l}\text { Стратегические. Тактические (организационно-технологические). Операционные (фи- } \\
\text { нансово-экономические) }\end{array}$ \\
\hline
\end{tabular}


и последствий, применяются разные модели, стратегии и инструменты антикризисного менеджмента. Так в источнике [1] описаны модели антикризисного менеджмента по отношению к отдельным параметрам кризиса. По нашему мнению, это скорее поведенческие стратегии, которые используются ситуационно согласно с выделенными параметрами:

- в зависимости от влияния на начало кризисного периода: приближение, которое состоит в создании условий для ускорения кризиса; отдаление как создание условий для отсрочки кризиса; невмешательство как игнорирование ситуации, отсутствие управленческих усилий на начало кризиса;

- в зависимости от влияния на конечный результат: предупреждение возникновения как подготовка и реализация управленческих мер, которые делают невозможным возникновение кризисных явлений; стабилизация положения, когда основное внимание уделяется обеспечению управляемости системы в условиях кризисного состояния; приспособление как минимизация внешних негативных последствий влияния использования возможностей положительных влияний; выход из кризиса как завершение кризисного периода независимо от его последствий, в том числе негативных;

- в зависимости от характера поведения на протяжении кризисного периода: содействие развитию как реализация мер, нацеленных на ускорение противоречий, активизация их проявления; нейтралитет как непринятие управленческих мер, а только накопление ресурсов; борьба с негативными проявлениями и последствиями;

- в зависимости от объекта управленческих усилий: последствия кризиса - антикризисное управление ориентированное на минимизацию негативных последствий кризиса; причины кризиса - управление направленное на локализацию или устранение причин кризиса; продолжительность кризиса - сокращение срока кризиса; комбинированное антикризисное управление;

- в зависимости от привлечения внешних ресурсов и специалистов: внешнее антикризисное управление; внутреннее антикризисное управление; комбинированное антикризисное управление [1].

Разнообразие взглядов о природе возникновения кризисных ситуаций привела к тому, что ученые выделяют разные инструменты антикризисного менеджмента. Они существенно отличаются по направлению действия и силе влияния, группами субъектов менеджмента, которые их используют.

Использование одного или одновременно нескольких инструментов происходит на определённом этапе процесса антикризисного менеджмента, основные из которых: выявление признаков кризиса, определение степени потенциального или реального негативного влияния определённых факторов (угроз) на состояние предприятия; оценка ресурсного потенциала антикризисного менеджмента для проведения антикризисных мер; диагностика кризисных явлений и угрозы банкротства предприятия; определение цели и задачи антикризисного менеджмента; выбор методов, инструментов и приемов антикризисного менеджмента; разработка антикризисных мер или программы; реализация антикризисных мер или программы антикризисного менеджмента, контроль деятельности; корректирующие действия; оценка эффективности антикризисных мер и управленческих решений; разработка профилактических мер, направленных на избежание повторения кризиса.

Так как инструменты операционного уровня применяются в системе менеджмента предприятия традиционно, детальнее рассмотрим инструменты стратегического и тактического уровня. В антикризисном менеджменте особое место занимает маркетинг, так как систематическое сканирование внешней среды предприятия позволяет получать сигналы, которые свидетельствуют о возможной угрозе или появлении дополнительных возможностей для предприятия. В кризисных условиях важно иметь надежных партнеров и поставщиков, поддерживать связи и контакты с потребителями.

Актуализируется антикризисное инновационное управление предприятием, антикризисная кадровая политика. Последняя должна быть реалистичной, творческой, ориентированная на привлечение профессионально подготовленных, с новаторскими задатками людей. При невозможности удержания собственного подразделения, которое занималась бы антикризисным менеджментом, целесообразно использовать консалтинг как получение услуг по рациональному использованию потенциала и ресурсов предприятия для достижения намеченных це- 
лей преодоления кризиса.

Диверсификация является активным методом реагирования на внешние угрозы. Использование стратегии диверсификации позволяет предприятиям создавать принципиально новые товары и услуги на базе использования прогрессивных технологий, развивать новое направление предпринимательства, повышать качественные характеристики продукции, которые изготавливаются, активизировать свою политику на рынке, что в совокупности направлено на оздоровление предприятия, обеспечение его стабильности и развитие.

Реинжиниринг бизнес-процессов в системе антикризисного менеджмента - это совокупность принципов, подходов, процедур и методов, нацеленных на кардинальные стратегические изменения, которые позволяют значительно повысить результативность деятельности предприятия и достичь стратегических целей развития. Использование этого инструмента позволяет выделить и осуществить коренные изменения тех цепочек бизнеса, которые обеспечат прорыв и долгосрочное конкурентное преимущество. Целью реинжиниринга бизнес-процессов является повышение качества системы управления предприятием в ключевых сферах деятельности для формирования конкурентных преимуществ, увеличение уровня конкурентоспособности, экономической эффективности и развития. Основные задачи реинжиниринга бизнес-процессов: смена организационной структуры предприятия с функциональной на кросс-функциональную (бригадная) или горизонтальную на уровне топ-менеджмента и бригадную - на уровне бизнес-процессов; формирование системы мотивации к самостоятельной работе, инициативности в пределах процессов, оценки и награды за полученный результат; формирование новой корпоративной культуры на основе максимального удовлетворения потребностей потребителей.

Антикризисный менеджмент на базе контроллинга в краткосрочном периоде предвидит выживание предприятия, нацеленное на обеспечение прибыльности, а в долгосрочном - на реализацию разработанных стратегических планов в границах допустимых (принятых) отклонений. Средства контроллинга позволяют выявить проблемы, которые возникли в процессе реализации антикризисной стратегии, устранить отклонения путём корректировочных дей- ствий на основе разработанных альтернативных вариантов.

Для консолидации факторов внутренней и внешней среды предприятия эффективным инструментом является интеграция, которая способствует построению законченных технологических цепочек, снижению затрат на одну продукцию, росту продуктивности труда, повышению финансовой стабильности и устойчивости предприятий, снижению уровня неопределенности в поставках и сбыте продукции, снижению рисков. Горизонтальная интеграция обычно осуществляется с целью углубления специализации, увеличения и улучшения качества продукции, повышения эффективности деятельности путем увеличения масштабов, экономии постоянных затрат на единицу продукции, увеличения части рынка и степени экономической концентрации в отрасли. Вертикальная интеграция предусматривает создание специфических межотраслевых производственных связей, которые обеспечивают последовательный технологический процесс от производства сырья до реализации продукции. Использование этого инструмента позволяет удешевить приобретение ресурсов, снизить трансакционные затраты, повысить тем самым финансовую устойчивость и конкурентоспособность предприятия.

В условиях, когда кризис наступил, но предприятие имеет реальную возможность восстановить платежеспособность, ликвидность и прибыльность, принимается решение о проведении санации. Санация может происходить путем: слияния предприятия, которое находится на грани банкротства с более мощным; выпуска новых акций или облигаций для мобилизации финансовых ресурсов; кредитования и субсидии; преобразования краткосрочной задолженности в долгосрочную и так далее. То есть, это комплекс последовательных, взаимосвязанных мер, направленных на выведение субъекта хозяйствования из кризиса, восстановления его прибыльности и конкурентоспособности в долгосрочном периоде.

Реструктуризация предусматривает осуществление организационно-экономических, правовых, технических мер, направленных на изменение структуры предприятия, его управление, формы собственности, организационно-правовые формы, с целью улучшения экономических и финансовых показателей функционирования, привлечение инвестиций; 
усиление конкурентоспособности компании за счёт слияния или поглощения. Единой универсальной модели реструктуризации не существует. Ее содержание определяют размер, структура, технологии, ресурсы, квалификация персонала, уровень менеджмента, текущее состояние предприятия.

Процедура банкротства как метод антикризисного управления предусматривает оздоровление экономики предприятия-должника в условиях потенциальной возможности восстановления платежеспособности путем реализации части его имущества и осуществлении других организационных и экономических мер с целью продолжения его деятельности.

Таким образом, каждый из представленных инструментов используется на определённом этапе разрастания кризиса. Так, контролинг эффективно использовать постоянно, это может быть вмонтированный в систему менеджмента инструмент, но главная его роль как превентивного, вызванного распознать и слабые сигналы с помощью методов диагностики кризисного состояния. Интеграция любого типа предусматривает существенные затраты времени и усилий на поиски партнера для обеспечения реализации интересов предприятий-участников, что не всегда возможно. Диверсификация - достаточно затратная процедура, требующая длительного подготовительного и инвестиционного периода, свободных ресурсов, достаточного потенциала для дальнейших преобразований. Реинжиниринг бизнес-процессов в общем рассматривается как эффективное средство управ- ления, которое дает возможность осуществить “прорыв”, так как дает возможность эффективно управлять бизнес-процессами и предприятием в целом; руководство получает оперативную и достоверную информацию о принятии управленческих решений, возможность контролировать деятельность структурных подразделений, групп бизнес-процессов; меняются функции менеджера с контролирующий на координирующую, основная роль - помощь в решении проблем, которые возникают у них в ходе выполнения бизнес-процесса. Финансовая санация и процедура банкротства инструменты, которые используются в кризисном периоде, когда внутренних ресурсов предприятия недостаточно, но возможности выхода из кризиса ещё есть.

Выводы. Таким образом, стратегические изменения могут быть обусловлены чередой причин, и руководители предприятия должны быть к ним готовы. Эта готовность определяется не только умением распознавать, адаптироваться к влиянием внешней среды, но и выбирать наиболее адекватные инструменты по ситуации. Важно, чтобы было понимание, при каких обстоятельствах усовершенствование существующей системы менеджмента не даст ожидаемых результатов и необходимы кардинальные меры. Указанные стратегические инструменты дают возможность не только не допустить разрастания кризисов, но и возможность получить долгосрочное конкурентное преимущество, восстановить устойчивость предприятия к агрессивным факторам внешней среды.

\section{Библиографический список}

1. Антикризисное управления предприятием: электронный начальный помощник [Электронный ресурс] http://library.if.ua/books/6.html

2. Градов А.И. Стратегия экономического управления предприятием Санкт-Петербург. 1993.375 с.

3. Грибан С.В. Система антикризисного управления предприятием [Электронный ресурс] //Эффективная экономика. 2013. № 11.

4. Грязнова А.Г. Антикризисный менеджмент / А.Г. Грязнова, М.А. Федотова, А.Н. Маринюк и др.; под ред. А.Г. Грязновой. Москва. 1999. 368 с.

5. Лигоненко Л.О. Антикризисное управление предприятием: монография. Киев. 2001.580 с.

6. Маховка В.М. Методология формирования системы антикризисного управления предприятия [Электронный ресурс] // Инновационная экономика. 2013. № 39. С. 105.

7. Непочатенков О.О. Финансовый менеджмент / О.О. Непочатенков, Б. С. Гузар. Киев. 2013. 496 с.

8. Рязанова О. Е., Левченко Л.В. Инвестиционный климат как условие для развития инновационной экономики // Экономические науки. 2014. № 114. С. 14-28.

9. Урумова Ф.М. Классификация общественных институтов и эффективность их реализации // Экономический журнал. 2005. № 1 (9). С. 75-92. 